\section{RETINAL TOXICITY DUE TO HYDROXYCHLOROQUINE IN A SINGLE CENTER SYSTEMIC LUPUS ERYTHEMATOSUS COHORT}

${ }^{1}$ Yesid J Portilla*, 'Diego Marino, 'Sheyla Leal Castro, 'Ramiro Gomez, ${ }^{2}$ Diana Dubinsky, ${ }^{1}$ Marina Garcia, Yuly Cuellar. ${ }^{1}$ University of Buenos Aires; ${ }^{2}$ Sanatorio Guemes

10.1136/lupus-2019-|sm.151

Background The use of Hydroxychloroquine (HCQ) in Systemic Lupus Erythematosus (SLE) has been shown to decrease disease activity and all cause mortality. Retinal toxicity (RT) may limit its use and the pathogenesis of RT has not been fully established.

The aim of this study is to evaluate retinal toxicity in our SLE cohort.

Methods Our electronic SLE database (Jan 2014-June 2018) was evaluated. Patients fulfilling ACR 1997 criteria, with at least 1 year follow-up, at leats 12 week of HCQ treatment and computerized visual field (CVF) study performed who suspended HCQ due to RT were included. Patients with other HCQ suspension causes (intolerance, hypersensibility, muscular toxicity, skin rash) were excluded.

RT was defined as diminution in visual acuity and/or worsening in CVF below reference levels that required HCQ suspension or dose adjustment.

Other possible causes of retinal alteration (diabetes, arterial hypertension), cumulative dose of HCQ at the time of suspension, time of HCQ exposure and accrual damage by SLICCDI at the time of suspension and at the last recorded visit were assessed.

Results 231 patients evaluated. 33 included. 10 (30\%) reinitiated treatment at a later time, 5 with dose adjustment. HCQ suspension was definite in $23(69.7 \%, 9.9 \%$ of the global population).

Patients with RT had mean age 44.5 (DS $\pm 12,6$ ) years; Ethnicity: Amerindian 6,06\%, Caucasian 6,06\% and Mestizo 87,8\%; $12(36.3 \%)$ had arterial hypertension and 2 (6.06\%) diabetes.

Median Cumulative dose of HCQ at suspension was 576 gr (IQR 144-1008). 9 (27.2\%) patiens had cumulative dose $>1000$ gr and $13(39.3 \%)>5$ years of exposure.

Mean SLICC-DI at suspension was 0.8 (DS $\pm 1,2)$ and mean SLICC-DI at last visit was 1,17 (DS $\pm 1,7$ ).

$22(70.9 \%)$ patients with CVF worsening were receiving $\mathrm{HCQ}>5 \mathrm{mg} / \mathrm{kg}$ (real weight) and $23(74.1 \%)$ were receiving $\mathrm{HCQ}>6.5 \mathrm{mg} / \mathrm{kg}$ (ideal weight)

Conclusions We observed a similar frecuency of HCQ suspension due to RT as reported in other studies. In our patients, there was no difference in RT between patients receiving $<5 \mathrm{mg} / \mathrm{kg}$ (real weight) vs $<6.5 \mathrm{mg} / \mathrm{kg}$ (ideal weight).

We found a higher frecuency of RT in patients with cumulative dose of HCQ $<1000 \mathrm{gr}$ and $<5$ years of HCQ exposure. This might challenge the American Society of Ophthalmology recommendation of CVF after 5 years of exposure or $>1000 \mathrm{gr}$ of cumulative dose.

A raise in the SLICC-DI score was observed after HCQ discontinuation, reaffirming the role of HCQ therapy in SLE.

A limitation is that RT was defined by CVF and was not routinely assessed by higher complexity studies (OCT). As a strength, RT was studied in the Mestizo population of Argentina, the dominant ethnicity, which might not be fully represented in previous international studies.

\begin{tabular}{lll} 
Abstract 151 Table 1 & Cumulative dose in years & \\
\hline Year $\mathrm{Kg}$ & $<1000$ & $>1000$ \\
\hline$<5$ & $20 / 33(60,6 \%)$ & 0 \\
$>5$ & $4 / 33(12,1 \%)$ & $9 / 33(27,2 \%)$ \\
\hline
\end{tabular}

Funding Source(s): None

\section{MEN AND SEXUAL FUNCTION: AN OVERLOOKED ISSUE IN SYSTEMIC LUPUS ERYTHEMATOSUS}

'Javier Merayo-Chalico*, 'Jonathan Campos-Guzmán, ' Ana Barrera-Vargas, 'Diana GómezMartín, 'Samuel Govea-Pelaez, ${ }^{1} J$ orge Alcocer-Varela, ${ }^{1}$ Miguel Ángel Gómez-Sámano, ${ }^{2}$ Diana Marcela Padilla-Ortíz. ${ }^{1}$ Instituto Nacional de Ciencias Médicas y Nutrición "Salvador Zubirán"; " Universidad de La Sabana

\subsection{6/lupus-2019-Ism.152}

Background Whereas SLE is uncommon in men, the disease is usually more severe and requires more aggressive immunosuppression in male patients. There are multiple studies regarding sexual aspects in women with SLE, but information about sexual function in male patients is quite scant.

Methods We performed a longitudinal study in a third-level referral center in Mexico City (January-November 2018). We included men aged 16 years who fulfilled ACR criteria for SLE and who were sexually active in the previous six months. All subjects answered the International Index of Erectile Function-15 (IIEF-15), the SF-36 (which determines generic health-related quality of life) and the HAQ in two visits. Other clinical, serological and demographic variables were measured. Oxidized LDL was quantified by ELISA.

Results We included 108 male SLE patients. Mean age was $37.2 \pm 1.1$ years and most patients $(87.9 \%)$ were taking immunosuppressive therapy. Comorbidities were present in $58.3 \%$ of subjects, with dyslipidemia and hypertension being the most prevalent $(34.2 \%$ and $28.7 \%$, respectively).

The prevalence of sexual dysfunction (SD) was $53.7 \%$. In the basal visit, the only significant differences between the patients with SD and those without SD were a lower education degree $(p=0.007)$ and persistent lymphopenia $(p=0.01)$. There was a positive correlation between global IIEF-15 score (gsIIEF-15) and global SF-36 score $(r=0.459, p=0.0001)$. The physical function domain had the highest correlation $(\mathrm{r}=0.509, \mathrm{p}=0.0001)$. Likewise, there was a weak negative correlation between gsIIEF-15 and HAQ score $(\mathrm{r}=-0.252$, $\mathrm{p}=0.012$ ). Also, the gsIIEF-15 had a weak correlation with the absolute lymphocyte count $(\mathrm{r}=0.273, \mathrm{p}=0.005)$ and oxidized LDL $(r=0.310, p=0.04)$.

In the follow-up visit the only significant differences between the patients with SD when compared with subjects without SD was a low absolute lymphocyte count (1031 \pm 89 vs $1458 \pm 119, p=0.005)$; the correlations mentioned in the baseline visit remained significant. Regarding erectile 
Abstract 152 Table 1 Demographic, clinical and laboratory features (basal outpatient visit)

\begin{tabular}{|c|c|}
\hline Variable & Mean \pm SEM \\
\hline \multicolumn{2}{|l|}{ Demographic } \\
\hline Age (years) & $37.2 \pm 1.1$ \\
\hline Body mass index $\left(\mathrm{kg} / \mathrm{m}^{2}\right)$ & $26.5 \pm 0.4$ \\
\hline Less than 10 years of schooling $(n, \%)$ & $21 / 108(19.4)$ \\
\hline Time since SLE diagnosis (years) & $9.1 \pm 0.6$ \\
\hline Time between visits (weeks) & $17.9 \pm 1.1$ \\
\hline \multicolumn{2}{|l|}{ Clinical Features } \\
\hline Total score IIEF-15 (reference interval: 5-75 points) & $58.7 \pm 1.3$ \\
\hline Erectile function (reference interval: $1-30$ points) & $23.9 \pm 0.6$ \\
\hline Intercourse satisfaction (reference interval: 0-15 points) & $10.9 \pm 0.3$ \\
\hline Orgasmic function (reference interval: 0-10 points) & $8.1 \pm 0.2$ \\
\hline Sexual desire (reference interval: $2-10$ points) & $7.5 \pm 0.1$ \\
\hline Overall satisfaction (reference interval: $2-10$ points) & $8.1 \pm 0.1$ \\
\hline Total score SF-36 (reference interval: 0-100 points) & $69.2 \pm 1.3$ \\
\hline Physical component summary score (reference interval: 0-100 points) & $71.4 \pm 1.8$ \\
\hline Mental component summary score (reference interval: 0-100 points) & $67.0 \pm 1.1$ \\
\hline Total score HAQ (reference interval: 0-3 points) & $0.16 \pm 0.03$ \\
\hline Secondary antiphospholipid syndrome (n, \%) & $16 / 108(14.8)$ \\
\hline SLEDAI score (points) & $4.2 \pm 0.4$ \\
\hline Others comorbidities $(\mathrm{n}, \%)$ & $63 / 108(58.3)$ \\
\hline Smoking $(\mathrm{n}, \%)$ & $30 / 108(27.7)$ \\
\hline \multicolumn{2}{|l|}{ Laboratory features } \\
\hline Hemoglobin $(\mathrm{mg} / \mathrm{dl})$ & $15.3 \pm 0.2$ \\
\hline Leukocytes $\left(\mathrm{mm}^{3}\right)\left(\times 10^{3}\right)$ & $5.9 \pm 0.2$ \\
\hline Absolute lymphocyte count $\left(\mathrm{mm}^{3}\right)$ & $1362.6 \pm 76.0$ \\
\hline Absolute neutrophil count $\left(\mathrm{mm}^{3}\right)$ & $3826.2 \pm 166.8$ \\
\hline Neutrophil-to-lymphocyte ratio & $4.1 \pm 0.5$ \\
\hline Platelets $($ cells $/ \mu \mathrm{l})\left(\mathrm{x} 10^{3}\right)$ & $215.4 \pm 6.6$ \\
\hline Total cholesterol/HDL ratio & $4.5 \pm 0.2$ \\
\hline Serum creatinine $(\mathrm{mg} / \mathrm{dl})$ & $1.4 \pm 0.1$ \\
\hline C3 levels (reference interval:87-200 mg/dl) & $104.1 \pm 3.2$ \\
\hline C4 levels (reference interval: $19-52 \mathrm{mg} / \mathrm{dl}$ ) & $19.7 \pm 1.2$ \\
\hline Anti-dsDNA antibodies (reference interval: $\leq 9.6 \mathrm{Ul} / \mathrm{ml}$ ) & $208.2 \pm 70.4$ \\
\hline Use of immunosuppressive treatment $(n, \%)$ & 95/108 (87.9) \\
\hline Prednisone $(n, \%)$ & $58 / 108(53.7)$ \\
\hline Current dose (mg/day) & $6.4 \pm 1.0$ \\
\hline Azathioprine $(\mathrm{n}, \%)$ & $31 / 108(28.7)$ \\
\hline Current dose (mg/day) & $28.2 \pm 4.7$ \\
\hline Antimalarial $(\mathrm{n}, \%)$ & $73 / 108(67.5)$ \\
\hline Current dose (mg/day) & $146.0 \pm 11.1$ \\
\hline Mycophenolate mofetil $(\mathrm{n}, \%)$ & $42 / 108(38.8)$ \\
\hline Current dose (mg/day) & $680.5 \pm 89.8$ \\
\hline Cyclophosphamide exposure previous 6 months (n, \%) & $7 / 108(6.4)$ \\
\hline Cumulative dose (previous 6 months) (mg) & $290 \pm 120.5$ \\
\hline Anticoagulation $(n, \%)$ & $18 / 108(16.6)$ \\
\hline Non-immunosuppressive treatment $(n, \%)$ & $85 / 108(78.7)$ \\
\hline
\end{tabular}


function, $44 \%$ of the subjects had some degree of dysfunction. The rest of the variables are shown in table 1.

Conclusions Sexual function is affected in men with lupus (mostly young and with adequate functional capacity), regardless of comorbidities and treatment. Interestingly, lymphopenia is persistently associated with an impaired sexual function, which could be related to the role it plays in endothelial dysfunction and atherosclerosis. The patients disease perception, which is influenced by their academic level and physical role in their daily activities, seems to affect their sexual performance and quality of life. These findings reinforce the need of a multidisciplinary approach for male SLE patients with sexual dysfunction.

Funding Source(s): None

\section{INCIDENCE AND RISK FACTORS FOR PROGRESSION OF CORONARY-ARTERY CALCIFICATION IN PATIENTS WITH SYSTEMIC LUPUS ERYTHEMATOSUS (SLE)}

${ }^{1}$ Mario Cesar Ocampo-Torres, ${ }^{1}$ Gabriela Hernandez-Molina, ${ }^{2}$ Sergio Criales, ${ }^{1}$ Juanita Romero-Diaz*. ${ }^{1}$ Instituto Nacional de Ciencias Médicas y Nutrición S.Z; ${ }^{2}$ Instituto Nacional de Cardiologia Ignacio Chavez

10.1136/lupus-2019-Ism.153

Background Premature atherosclerosis has been recognized as a major cause of morbidity and mortality in SLE patients. Whether the effect of risk factors for cardiovascular disease in patients with lupus change over time is still unknown. We aimed to identify the incidence and risk factors for progression of coronary-artery calcification (CAC) in SLE patients.

Methods Design: Inception Cohort. Since enrollment into the cohort, all patients had a standardized medical history, physical examination, and laboratory tests, including lipid profile, apoB, homocystein, high-sensitivity C-reactive protein (hs$\mathrm{CRP}$ ), serum complement (C3 and $\mathrm{C} 4$ ), and autoantibodies. Every 3-6 months, patients have been seen at the lupus clinic for medical care, and assessments of disease activity using the SLE disease activity scores, and medications usage.
Every year, information has been updated, including irreversible damage accrual, any co-morbidities, traditional cardiovascular risk-factors, and a blood sample has been drawn. In 2008, 104 lupus patients from the cohort (93\% females) was screened for coronary-artery calcifications using Multidetector Computed Tomography, after 5.1 years of follow-up. In 2018 a follow-up screening for CAC was carried-up. CAC was considered as positive if i) patients without $\mathrm{CAC}$ in 2008 were found with CAC + in the second screening or ii) patients with CAC positive in 2008 were found with any increase of their Calcium Score. Correlates for calcifications were analyzed. Cumulative incidence of CAC was calculated and risk factors for CAC progression were identified by multivariate analysis.

Results At-enrollment into de cohort, lupus patients were 27.2 +9.1 years of age and disease duration $5.4+3.8$ months. On 2008 during the first screening, coronary-artery calcification were detected in $7.2 \%$ patients, since age 23 years, and from three years of diagnosis. At follow-up screening, progression of CAC was identified in 16.3\% (IC95\% 10.4-24.6). Cumulative incidence of CAC was observed in 9\%. Earlier Risk factors associated with CAC were disease activity $(p=0.03)$ and disease duration $(p=0.03)$ while risk factors for progression of CAC were postmenopausal status $(p=0.01)$, apoB levels $(\mathrm{p}=0.01)$.

Conclusions Our findings suggest that in patients with SLE earlier CAC is associated with disease severity while in the progression of CAC, traditional risk factors for atherosclerosis were adding.

Funding Source(s): None

\section{IMPACT OF DIAGNOSIS AGE ON QUALITY OF LIFE AMONG PATIENTS WITH SYSTEMIC LUPUS ERYTHEMATOSUS}

${ }^{1}$ Christina L Kearse* ${ }^{2}$ Robert Campbell, ${ }^{3}$ Jim Oates, ${ }^{3}$ Gary S Gilkeson, ${ }^{3}$ Diane L Kamen. ${ }^{1}$ College of Medicine, Medical University of South Carolina; ${ }^{2}$ Center for Health Analytics and Discovery, Eastern Virginia Medical School; ${ }^{3}$ Division of Rheumatology and Immunology, Medical University of South Carolina

10.1136/lupus-2019-Ism.154

\begin{tabular}{|c|c|c|c|}
\hline Domain & $\begin{array}{l}\text { aSLE }(n=323) \\
\text { Mean } \pm \text { SD }\end{array}$ & $\begin{array}{l}\operatorname{cSLE}(n=9) \\
\text { Mean } \pm \text { SD }\end{array}$ & P Value \\
\hline \multicolumn{4}{|l|}{ Physical Health } \\
\hline Physical Functioning & $38.8 \pm 12.4$ & $52.1 \pm 6.1$ & $0.002 *$ \\
\hline Role Physical & $38.5 \pm 12.5$ & $50.1 \pm 7.1$ & $0.007^{*}$ \\
\hline Bodily Pain & $41.8 \pm 11.3$ & $48.0 \pm 11.3$ & 0.103 \\
\hline General Health & $37.7 \pm 11.3$ & $41.7 \pm 7.9$ & 0.289 \\
\hline \multicolumn{4}{|l|}{ Mental Health } \\
\hline Vitality & $43.1 \pm 11.6$ & $50.4 \pm 8.6$ & 0.064 \\
\hline Social Functioning & $40.7 \pm 12.7$ & $46.5 \pm 8.3$ & 0.172 \\
\hline Role Emotional & $41.0 \pm 14.9$ & $48.5 \pm 8.1$ & 0.133 \\
\hline Mental Health & $45.3 \pm 13.5$ & $48.8 \pm 12.5$ & 0.442 \\
\hline
\end{tabular}

